\title{
Archéopages
}

Archéopages

Archéologie et société

Hors-série 2 | 2010

Archéologie sans frontières

\section{L'approche géomorphologique du site de Lalibela}

\section{Laurent Bruxelles}

\section{CpenEdition}

Journals

Édition électronique

URL : https://journals.openedition.org/archeopages/762

DOI : 10.4000/archeopages.762

ISSN : 2269-9872

\section{Éditeur}

INRAP - Institut national de recherches archéologiques préventives

\section{Édition imprimée}

Date de publication : 1 octobre 2010

Pagination : 45

ISSN : $1622-8545$

\section{Référence électronique}

Laurent Bruxelles, "L'approche géomorphologique du site de Lalibela », Archéopages [En ligne], Horssérie 2 | 2010, mis en ligne le 01 octobre 2010, consulté le 23 février 2023. URL : http://

journals.openedition.org/archeopages/762 ; DOI : https://doi.org/10.4000/archeopages.762 
pas de réoccupation majeure de nature résidentielle par exemple. Le mobilier recueilli est donc susceptible de fournir une image assez juste des céramiques utilisées dans l'église pendant ses différentes périodes d'occupation. Le corpus ainsi obtenu pourra servir de base de comparaison pour des recherches futures dans cette région, en vue notamment d'établir des parallèles chronologiques. À titre d'hypothèse de travail, une distinction a été faite entre les récipients qui pourraient avoir un lien étroit avec les activités spécifiques pratiquées dans un lieu de culte et les autres formes qui paraissent relever d'une utilisation domestique de la céramique. [Fig.1] Aux premiers répondent les coupelles de petite taille, compactes et massives (formes 1,5 et 10), en lien vraisemblable avec l'utilisation de l'encens. La forme 1 présente d'ailleurs une stricte analogie morphologique avec les coupelles à encens contemporaines. Les secondes semblent en lien avec l'emploi de denrées consommables : cuisson des aliments ( « plats à inger ${ }^{7}$ » de forme 2), stockage des denrées (forme 3), préparation et présentation des aliments (coupes carénées de forme 4 et autres plats), approvisionnement et stockage de l'eau (pots à eau de forme 7), service des liquides avec les cruches et/ou vases de forme 6-8, voire préparation de laitages avec des panses perforées assimilables à des faisselles.

Par ailleurs, l'examen des céramiques recueillies dans un contexte particulier de l'édifice (fosse F1) permet de poser l'hypothèse d'un mobilier liturgique prestigieux, dont l'usage est réservé aux prêtres, par la présence de céramique importée (Céladon de Chine) et de vases a priori antérieurs à la phase d'occupation de l'église, qui trouvent des parallèles morphologiques auprès des céramiques de la culture Shay, illustrée dans la présente livraison par les vases du tumulus de Tater Gur (cf. encadré p. 4.1). Ces vases plus anciens pourraient devoir leur conservation à la nature sacrée du lieu.

Les tentatives de mise en parallèle des mobiliers céramiques des deux sites tendent à exclure, pour le site de Meshala Maryam, toute occupation « royale » des lieux telle que la tradition orale pouvait le laisser envisager. Les vases présents témoignent d'une occupation humaine de nature domestique. Cette caractéristique, associée à l'absence de mobilier de prestige ou importé, ne permet pas de déceler sur ce site l'empreinte d'un roi et de sa cour, fût-elle itinérante comme en ces temps médiévaux.

Ce travail est à considérer comme un premier jalon dans la connaissance de la culture matérielle des sites médiévaux des hauts plateaux éthiopiens.
L'approche géomorphologique du site de Lalibela

$$
\begin{aligned}
& \text { Laurent Bruxelles } \\
& \text { Inrap }
\end{aligned}
$$

On peut se demander, a priori, ce que pourrait apporter un géomorphologue dans l'étude d'églises, fussent-elles creusées dans le roc. Mais rapidement, plusieurs faits ont été observés qui ont paru contribuer à la compréhension du site.

Tout d'abord, la forme des églises est directement conditionnée par la topographie initiale du secteur. Celles du groupe 1 sont alignées avec des toits à double pentes ; elles ont été creusées dans un relief particulièrement propice puisque la crête était orientée est-ouest. La ligne d'interfluve correspond peu ou prou au faîtage des églises. En revanche, dans le groupe 3, Beta Giyorgis a un toit plan, légèrement incliné, conformément à la pente du versant dans lequel il a été entaillé. Ensuite, le creusement dans ce site a bénéficié des scories basaltiques qui se prêtent particulièrement bien à la taille. Les parties les plus tendres de la roche ont été exploitées pendant les premières phases d'occupation du site (troglodytique et hypogées). Les phases ultérieures ont recoupé une roche basaltique beaucoup plus résistante à la taille, posant manifestement des problèmes techniques.

Enfin, nous avons réalisé un important travail d'identification et de topographie des déblais correspondant au creusement de chaque groupe d'églises. Ces tas, qui peuvent dépasser $20 \mathrm{~m}$ d'épaisseur, recèlent en leur sein une stratigraphie qui n'existe plus au niveau des bâtiments euxmêmes, puisqu'ils sont tous excavés. Nous disposons donc là du meilleur moyen de dater le site, mais aussi de caler les principales phases de creusement de chaque groupe d'églises.
Galette de céréal qui forme la base de l'alimentation. 